\title{
Avascular Necrosis
}

National Cancer Institute

\section{Source}

National Cancer Institute. Avascular Necrosis. NCI Thesaurus. Code C118385.

Tissue death resulting from an interruption to the blood supply. 